\section{Endoscopic removal of a piece of retained pancreatic stent with a novel new technique: turned guide-wire looping method}

Endoscopic placement of plastic stents to treat stricture of the main pancreatic duct (MPD) due to chronic pancreatitis has been widely accepted [1]. In spite of the improvement of endoscopic skills and devices, proximal migration is one of the most troubling problems. Here we describe a new technique for removing a pancreatic plastic stent (PPS) from the MPD.

We present a case of a 47-year-old woman with severe chronic pancreatitis who required repeat PPS replacement. A PPS was broken during removal, and the proximal piece of stent remained in the MPD ( Fig. 1). Attempts at extraction using a snare, forceps, basket, balloon, and Soehendra stent retriever failed. We then threaded a hydrophilic guide wire (Radifocus; Terumo, Tokyo, Japan) through the lumen of the retained stent. Because of severe stricture in the distal MPD, the tip of the guide wire was turned around and advanced alongside the stent toward the papilla, forming a loop in the MPD. The end of the guide wire exited the papilla and was grasped with biopsy forceps inside the duodenum ( $\mathbf{F i g} \mathbf{2}$ ). By gripping the other end outside the scope, the stent was successfully extracted (๑ Fig.3).

Proximal migration of a PPS is not a rare complication, occurring in up to $5.2 \%$ of patients [2]. Various techniques to remove a proximally migrated PPS have been reported $[3,4]$. However, the narrow and tortuous shape of the MPD, especially in chronic pancreatitis, may preclude several of these methods. In this case, a broken stent left in the MPD was successfully extracted by forming a loop with the guide wire. This technique may be a valid option for PPS removal when conventional methods fail.

Endoscopy_UCTN_Code_TTT_1AR_2AZ

Competing interests: None

\section{N. Takahara, H. Isayama, N. Sasahira, T. Hamada, R. Uchino, S. Mizuno, K. Miyabayashi, D. Mohri, K. Kawa- kubo, H. Kogure, T. Sasaki, N. Yama- moto, Y. Nakai, K. Hirano, M. Tada, K. Koike}

Department of Gastroenterology, Graduate School of Medicine, The University of Tokyo, Tokyo, Japan

\section{References}

1 Costamagna G, Bulajic M, Tringali $A$ et al. Multiple stenting of refractory pancreatic duct strictures in severe chronic pancreatitis: long-term results. Endoscopy 2006; 38 : 254-259

2 Johanson JF, Schmalz MJ, Geenen JE. Incidence and risk factors for biliary and pancreatic stent migration. Gastrointest Endosc 1992; 38: 341 - 346

3 Nambu T, Ukita T, Shigoka $H$ et al. Endoscopic retrieval of a disrupted pancreatic stent using a nasopancreatic drainage tube. Endoscopy 2010; 42: 308 - 309

4 Vila JJ, Ruiz-Clavijo D, Fernandez-Urien I et al. Endoscopic retrieval of a proximally migrated pancreatic stent: variation of the lasso technique. Endoscopy 2010; 42: 5-6

Bibliography

Dol http://dx.doi.org/

10.1055/s-0032-1309897

Endoscopy 2012; 44: E401

(c) Georg Thieme Verlag KC

Stuttgart · New York

ISSN 0013-726X

\section{Corresponding author \\ H. Isayama, MD, PhD}

Department of Gastroenterology

Graduate School of Medicine

The University of Tokyo

7-3-1 Hongo, Bunkyo-ku

Tokyo 113-8655

Japan

Fax: +81-3-38140021

isayama-tky@umin.ac.jp

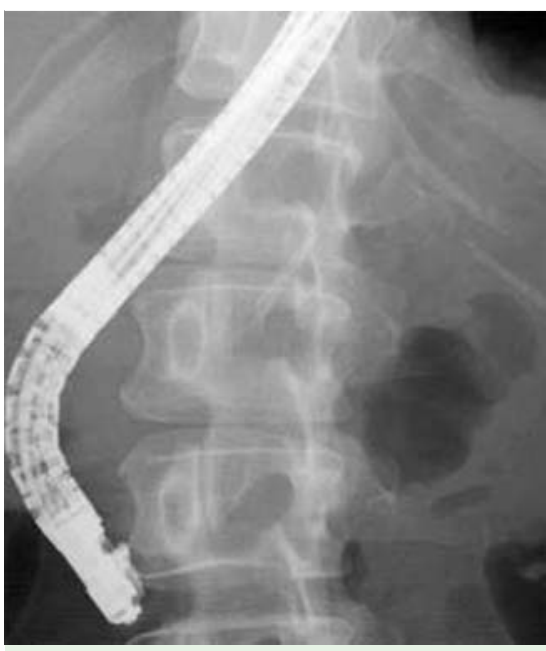

Fig. 1 A pancreatic plastic stent (PPS) was unintentionally broken, and the proximal piece of PPS left in the main pancreatic duct (MPD).

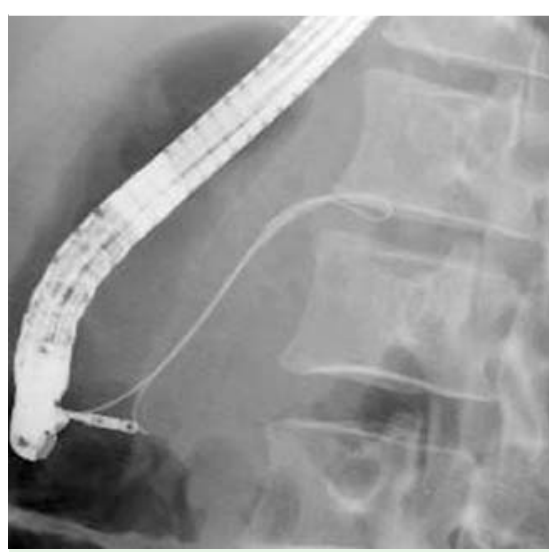

Fig.2 A guide wire was passed through the stent and successfully turned and advanced alongside the pancreatic plastic stent (PPS), with a loop formed in the main pancreatic duct (MPD). The end of the guide wire which came out from the papilla was grasped with biopsy forceps inside the duodenum.

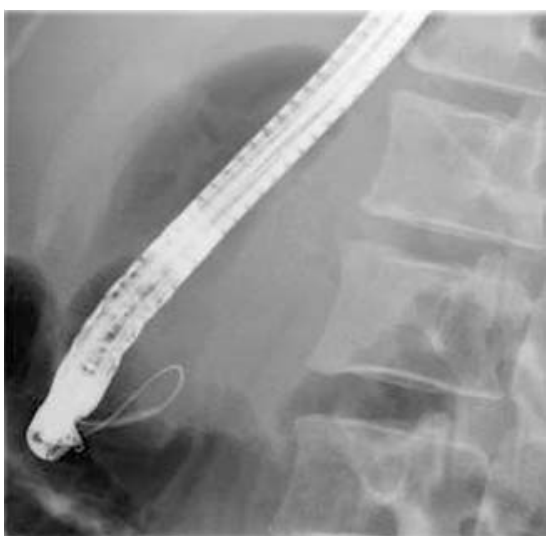

Fig. 3 By gripping both ends of the guide wire, it was possible to extract the pancreatic plastic stent (PPS). 